\title{
ITERATIVE 3D DEPTH MODEL BUILDING VIA ONE-PASS 3D DEPTH MIGRATION
}

IAN F. JONES

CGG, CGG House, 4 Dukes Green Avenue, Feltham, Middlesex TW14 OLR, UK

\begin{abstract}
.
With the advent of steep-dip non-dispersive isotropic 3D time and depth migration algorithms, the ability to image complex structures has entered a new phase. However, the most important issue in subsurface imaging is not the migration algorithm, but the elaboration of the subsurface velocity model.
\end{abstract}

Many conventional approaches to obtaining a migration velocity field involve Dix inversion of RMS stacking velocities, with appropriate editing and smoothing, leading to image ray, or normal ray map migration of picked time horizons to produce a final depth model.

In this paper, we concentrate our attention on the map migration step in this procedure, demonstrating the inability of map migration to yield a reliable depth model in the case of complex structures. We propose a viable alternative approach involving a 'layer stripping' model building technique, where each model horizon in turn is picked in depth migrated space. This involves repeated 'flooding' of the velocity-depth model with the (spatially varying) velocity of each successive layer; performing a one-pass 3D depth migration with the updated model; picking the consequently imaged depth horizon directly from the data; updating the model; and repeating the procedure for each layer in turn.

This approach guarantees coincidence of the final migrated result with the velocity-depth model. It does not guarantee validity of the interval velocity field. In order to facilitate modification of the velocity field, we also promote perturbation of the velocity within a given interval (typically over three percentage values): this results in three velocity-depth models with corresponding migrations. Interpretation of these three images for an horizon permits creation of a spatially variant percentage scale map in order to modify the interval velocity field to ensure improved imaging of the current horizon.

\section{INTRODUCTION.}

The fact that pre-stack 3D depth migration is still not commercially viable on an entire 3D data volume obliges us to use post-stack 3D depth migration. Fortunately, the cost of 3D post-stack depth migration has in recent years ceased to be a major factor in deterring people from performing depth migration. With improvements in the dip response and numerical isotropy of new algorithms (Hale, 1991a,b; Li, 1991, Jones, 1993a; Soubaras, 1992), software generated artefacts (Diet, 1984) have also become less of a concern.

However, the central issue in any imaging strategy remains not the migration itself, but the velocity field employed during that migration (Jones, 1993b). Several authors have suggested strategies for 2D pre-stack depth migration velocity model generation either by using focusing analysis (Yilmaz \& Chambers, 1984; Jeannot et al, 1986) or techniques involving a tomographic approach (Stork, 1992). However, as yet these techniques have not been generalised in practise to the 3D world, and to date focusing analysis itself does not take place in true 'migrated space'. Hence the reliability of the velocities thus determined is limited to the case of near-vertical incidence (Audebert \& Diet, 1990), although this failing has recently been addressed (Audebert, 1993). 
Here we elaborate on the methodology previously demonstrated and discussed by several authors (Cabrera et al, 1992; Johnson, 1992; Ratcliff, et al, 1992; Rockliff, et al, 1992; Wyatt, 1992): these approaches take their initial velocity field from interval velocities derived from RMS stacking velocities, with appropriate phases of smoothing and tying to wells.

Conventional post-stack approaches suffer in that in unmigrated data, it is often difficult to pick events, and, image ray depth conversion of picks made on time migrated data does not perform well below complex structures. In addition, we are faced with the problem of estimating interval velocities from RMS velocities using the Dix equation: the estimate grows progressively worse with increasing dip or depth, hence the reliability of horizon locations is compromised.

Cost constraints have to date limited the scope for fully flexible iterative migration: Wyatt et al (1992) for example used only two passes of depth migration, nevertheless obtaining excellent results having only had one pass at model updating on the basis of the first depth migration,

Here we use a technique keeping CPU times to below a few hours thus permitting perturbation of the velocity field to investigate lateral variations within layers while velocity 'flooding' below key horizons permits accurate 3D picking of subsequent horizons in depth migrated space. Essentially, we selectively decimate parameters for depth migration so as to minimise run-times whilst maintaining the integrity of the resultant image. Combining this strategy with application of an accurate one-pass 3D depth migration results in rapid robust imaging.

\section{CONVENTIONAL VERSUS ITERATIVE APPROACH.}

In the more conventional approach using map migrations, the errors associated with picking an horizon are 'propagated' and made worse during the process of map migration. That is to say, if the dip at a local area on an interface is in error, that dip error will be passed-on to the image ray (or normal ray) being employed to perform the map migration. With layer stripping depth migration, the inherent error in picking remains the same. However, as the picking takes place directly in depth migrated space, there is no further propagation of the error. In addition, when image ray migrations are performed (as opposed to normal ray migrations) there are approximations involved which break down as a function of dip severity.

A third point regarding the relative accuracy of the methods, is that when picking a complex structure, say for example the cap or sides of a salt dome (as considered here), there will always be regions of imprecise picking or zones where no picking is possible. A surface must be created from the grid nodes actually picked to give rise to the final interpolated gridded map (with a sample at every data location): this happens via some sort of surface fitting. When we pick the data in zero offset domain, the regions of ill-defined or undefined surface tend to be larger that they are for migrated data, hence more error is likely to occur during surface fitting.

In order for the methodology to be practical, each iteration of the migration on the entire areal coverage of the 3D migration must be carried-out with overnight turnaround. We achieved this by only migrating a grid of $25 \mathrm{~m} * 25 \mathrm{~m}$ using $1-30 \mathrm{~Hz}$. The production migration took place on a $12.5 \mathrm{~m}$ * $12.5 \mathrm{~m}$ grid using $1-70 \mathrm{~Hz}$. So essentially the model building runs were an order of magnitude faster than a production run.

\section{RESULTS AND CONCLUSIONS.}

We present a double salt dome example from the North Sea central graben: here deformation associated with the salt feature extends from the base of salt (below $7000 \mathrm{~m}$ ) to within a few hundred metres of the surface. An additional level of complexity for this data is the presence of anisotropic overlying shales, which preclude tying model depths to well log depths. This results in a vertical mispositioning in the depth migrated result, although lateral positioning should be accurate.

In all there were nine layers in the velocity-depth model. The first three layers were the same for both methods. The exercise of picking horizons for the map migration comparison was only 
performed for three layers in the model (layers 4-6). All interval velocity fields varied spatially, and some included a gradient.

In comparing migration results from the model generated by map migration with results from a model generated by layer stripping migration, the most obvious errors/differences occur in the 'saddle' region between the two salt domes, and on the steep flanks of the domes (figures $1 \& 2$ ). A pinch-out at CMP350, depth $3 \mathrm{~km}$, in the layer-stripping result is absent from the map migration result. Results from a velocity scan perturbing the chalk interval velocities by $+-3 \%$ show a surprising difference in the degree of focusing of the base chalk event.

The central issue in imaging complex structures is the elaboration of the velocity field. This is the key to any successful migration, whether it be post or pre stack. Iterative one-pass depth migration is shown to be a feasible approach to addressing the problem of velocity model elaboration. Additionally, conventional map migration is shown to be unreliable in complex areas.

\section{ACKNOWLEDGEMENTS.}

My thanks to my colleagues at CGG for their encouragement, especially J.P.Diet, R.Soubaras, I.Huard, J.Y.Blanc, and Keith Ibbotson; and to Mike Cooper and Mick Sugrue from BP Aberdeen for their support. Thanks also to BP, B.Gas, Ranger, Enterprise, \& Santos for their kind permission to use their data.

\section{REFERENCES.}

Audebert, F., \& Diet, J.P., 1990, A focus on focussing: 52nd Ann. Internat. Mtg. Soc. Expl. Geophys., 107-108.

Audebert, F., 1993, Migrated focus panels: 63rd Ann. Internat. Mtg. Soc. Expl. Geophys..

Cabrera,J., Perkins,W., Hagen, T., Ratcliffe, D.W., Lynn, W., 1992, 3D pre-stack depth migration: implementation and case history: 62nd Ann. Internat. Mtg. Soc. Expl. Geophys., Expanded Abstracts, 948-951.

Diet, J.P., 1984, A review of three dimensional migration theory and the laterally inhomogeneous case: 54th Ann. Internat. Mtg. Soc. Expl. Geophys., Expanded Abstracts, 447-449. 1770-1777. Hale, D., 1991a, Stable explicit depth extrapolation of seismic wavefields: Geophysics, 56,

Hale, D., 1991b, 3D depth migration via McClellan transforms: Geophysics, 56, 1778-1785. Jeannot, J.P., Faye, J.P., \& Denelle, E., 1986, Prestack migration velocities from depth focussing analysis: Geophysics, 45, 376-393.

36. Johnson, J.D., 1992, Structural imaging in the real world: The Leading Edge, v11, No.1, 32-

Jones, I.F., 1993a, Comparative anatomy of 3D one-pass depth migration schemes, 55 th Ann. Internat. Mtg. Europ. Assoc. Expl. Geophys., p116.

Jones, I.F., 1993b, 3D velocity model building via iterative one-pass depth migration 63rd

Ann. Internat. Mtg. Soc. Expl. Geophys. 974-977

$\mathrm{Li}, \mathrm{Z}$., 1991, Compensating finite difference errors in 3-D migration and modelling: Geophysics, 56, 1650-1670.

Ratcliff, D.W., Gray S.H., \& Whitmore Jr., N.D., 1992, Seismic imaging of salt structures in the Gulf of Mexico: The Leading Edge, v11,

Rockliff, D.G., Sugrue, M.J., Cooper, M.M., Pieprzak, A., Witcombe, M., Hodgkiss, G., 1992, 3D depth migration in the diapir province of the central North Sea: $62 \mathrm{nd}$ Ann. Internat. Mtg. Soc. Expl. Geophys., Expanded Abstracts, 925-926.

Soubaras, R., 1992, Explicit 3D migration using equiripple polynomial expansion and Laplacian synthesis: 62nd Ann, Internat. Mtg. Soc. Expl. Geophys., Expanded Abstracts, 905-908.

Stork, C., 1992, Making depth migration work in complex structures: 62 nd Ann. Internat. Mtg. Soc. Expl. Geophys., Expanded Abstracts, 939-943.

Wyatt, K.D., Towe, S.K., Layton, J.E., Wyatt, S.B., von Seggern, D.H., Brockmeier, C.A., 1992, Ergonomics in 3D depth migration: 62nd Ann. Internat. Mtg. Soc. Expl. Geophys., Expanded Abstracts, 944-947.

Yilmaz, O., \& Chambers, R., 1984, Migration velocity analysis by wavefield extrapolation: Geophysics, 49, 1664-1674. 

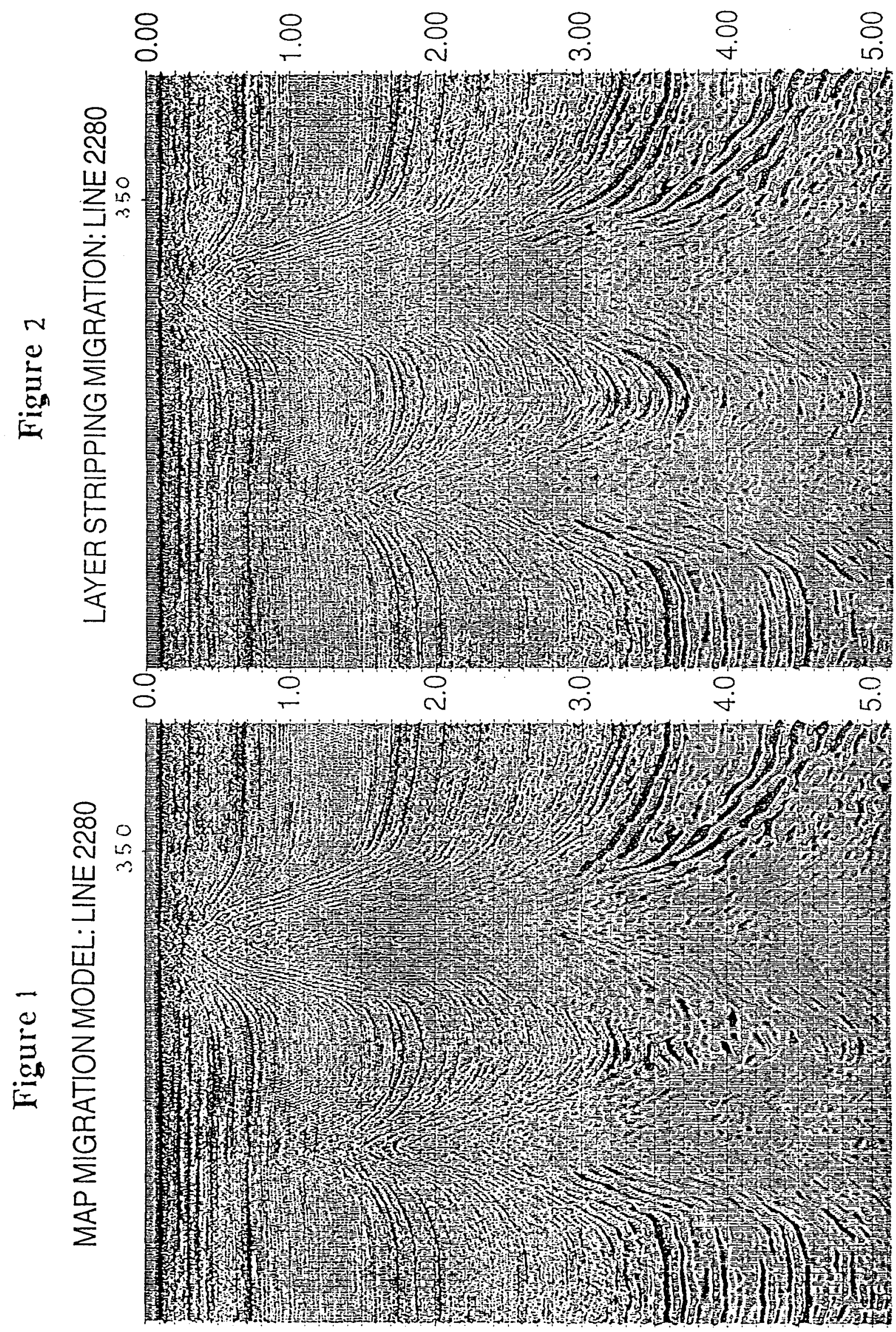

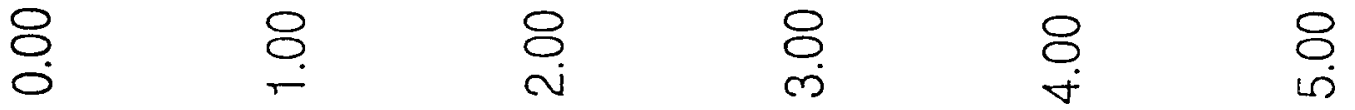

